\title{
Determinants of Students’ Academic Achievement in a Ghanaian University
}

\author{
Ibrahim Alhassan $^{1 *}$, Abukari Alhassan ${ }^{2}$ \\ ${ }^{1}$ Planning and Research Unit, University for Development Studies, Tamale, Ghana \\ ${ }^{2}$ Department of Statistics, Faculty of Mathematical Sciences, University for Development Studies, Navrongo, Ghana \\ *Corresponding author: ibrahim.alhassan@uds.edu.gh
}

Received November 22, 2018; Revised January 04, 2019; Accepted February 22, 2019

\begin{abstract}
The study was conducted to investigate the determinants of Students' Academic Achievement (SAA) in the University for Development Studies (UDS). Using a simple random sampling technique, 170 final-year students were sampled out of a total population of 362 expected graduates in the Faculty of Mathematical Sciences (FMS) at the $19^{\text {th }}$ Congregation of the University. A usable 145 questionnaires (85\% response rate) were retrieved and analyzed. Variables that were employed as determinants of SAA were students' age, their gender and the previous knowledge of their current programs. Students' Cumulative Grade Point Average (CGPA) was used as an indicator of SAA. The Dummy Variable Multiple Regression Analysis result showed that, SAA significantly varies directly with students' previous knowledge of their current programs, their gender and their age - in the order of their impact. The study supplements existing knowledge and literature in the area of measurement and evaluation of SAA.
\end{abstract}

Keywords: academic achievement, CGPA, educational institutions, students, UDS

Cite This Article: Ibrahim Alhassan, and Abukari Alhassan, "Determinants of Students' Academic Achievement in a Ghanaian University." American Journal of Educational Research, vol. 7, no. 2 (2019): 178-182. doi: 10.12691/education-7-2-11.

\section{Introduction}

Students are the most essential asset for any educational institution. This statement draws its strength from the fact that both teaching and non-teaching staff of educational institutions earned (monthly) income because of the services they provide to students; implying that without the students, educational institutions will cease to exist. Because of the forgoing reason, educational institutions must provide quality services to their students. Quality of education is oftentimes determined by the kind of graduates that an institution produces. These graduates are considered as educated when they exhibit certain traits that reflect the qualities of a well-educated person.

Education is generally regarded as a necessary and essential requirement for human development. It is central to socio-economic and technological advancements of the society; and it is critical to the self-generating process of positive transformation of nations, especially in Sub-Sahara Africa. Education is also mainly, about socialization and secondly, about the process of imparting knowledge for progress and development of both the individual and the society. It is not just about literacy and enlightenment. It is about value formation, value generation, and orientation handed down to an individual called student; to enable him/her fit well into a particular defined society as well as enable the individual to function as a social being.
Oftentimes, the degree to which a student is educated is influenced by the student's academic achievement; which is in tend determined by the student's class of graduation or Cumulative Grade Point Average (CGPA) that (s)he graduated with.

The question as to what determines Students' Academic Achievement (SAA) has not yet been fully answered. Because of this, educators and researchers have long been interested in identifying and understanding the variables that contribute to SAA [1].

Several studies have been conducted and voluminous literature documented on factors that affect SAA. The findings of some of these studies identified students' effort, previous schooling, parent's educational background, family income, self-motivation of students, age of students, learning preferences and entry qualification of students as important factors that have effect on SAA [2]. It is generally assumed that research findings may differ from one geographical setting to the other. Research findings may also differ resulting from the methodology employed.

Having armed themselves with this orientation and the fact that Deans of Faculties/Schools of the University will like to know the determinants of SAA; so as to enable them provide appropriate orientation to students, the researchers deemed it fit to conduct this study to investigate SAA using age of students, their gender and the previous knowledge of their current programs as the determinants of their academic achievements. 
In the light of the above reasons, the main objective of the study is to investigate the determinants of SAA. Specifically, the study seeks to determine the most influencing determinant of SAA in UDS and to test the appropriateness of the technique employed for the study.

The study, based on the foregoing, hypotheses that:

$\mathrm{H}_{1}$ : 'Age' has no significant impact on SAA.

$\mathrm{H}_{2}$ : 'Gender' has no significant impact on SAA.

$\mathrm{H}_{3}$ : 'Previous knowledge of program' has no significant impact on SAA.

\section{Literature Review}

The demand by industry to engage quality man-power so as to meet the socioeconomic developmental needs of developing countries has intensified the existing pressure on Higher Institutions of Learning (HIL) to produce quality graduates. Because of this, many governments, including that of Ghana, are concerned about the quality of services provided by their HIL [3]. This threat further places HIL in a position to appreciate the fact that quality service provision is no longer an option but a requirement and a contractual obligation that HIL owe their stakeholders [4].

Given that quality-consciousness is now the new normal in the provision of educational services in HIL, then management of universities as well as educators and researchers would have to become more concern about knowing the determinants of SAA. Several studies have been conducted for this purpose in the HIL context. Different determinants have been posited to affect SAA by different studies. For example, [1] finds out that gender, nationality, Extracuricullar activities, intention to pursue higher education and learning preferences significantly affect SAA.

The relationship between gender and the academic achievement of students has been discussed for decades [5]. A gap between the achievement of boys and girls has been found, with girls showing better performance than boys in certain instances [6]. Gender, ethnicity, and father's occupation are significant contributors to student achievement $[7,8]$.

While investigating the factors contributing to SAA in Islamia University Sub-Campus, [2] concludes that age of students, parent's socioeconomic status and daily study hours significantly contribute to SAA. The strength of correlation between each of the independent variables (age, parent's socioeconomic status and the daily study hours) and the dependent variable (SAA) suggests that daily study hours is positive and greater than the age and the father/guardian socioeconomic factors.

According to [9], a study was conducted by Borde (1998) to determine the extent to which factors like gender, age, academic origin, grade point average, extracurricular activities and employment influence the grades obtained in a course. The students in the research were taken from a public university in Florida. The results showed that gender, age and engagements in extracurricular activities were unrelated to SAA.

The most prevalent argument is that the socioeconomic status of learners affects the quality of their academic performance. Most of the experts argue that the low socioeconomic status has a negative effect on the academic performance of students because the basic needs of students remain unfulfilled and hence, they do not perform better academically (Adams, 1996 cited in [10]). The low socioeconomic status causes environmental deficiencies which results in low self-esteem of students [11].

Other studies hold opposing view that some of these determinants have no bearing on SAA. For example, after conducting a survey of 808 students from the Faculty of Economics and Business Administration at the Universidad Adres Bello on SAA, using socioeconomic status of parents, the Ordinary Least Square (OLS) and logistic regression analysis results of [12], showed no relationship, especially between SAA and the parents' socioeconomic factor.

The current study employs students' age, their gender and the previous knowledge of their current programs as determinants of their academic achievement; with CGPA considered as the best indicator of SAA.

\subsection{The Concept of CGPA}

One of the indicators that highlight the University students' qualification is their academic performance; which is mostly measured with the CGPA. The CGPA is an up-to-date assessment of the overall performance of a student from the time of his/her first registration. In other words, the CGPA is an assessment tool used to evaluate SAA. It is calculated to determine a student's current academic standing. CGPA remains the most widely used measure of SAA, perhaps it is because of the cumulative feature embedded in its derivation.

\subsubsection{Derivation of the CGPA}

The CGPA is the weighted average of the grade points (GPTs) obtained in all courses registered by a student since (s)he entered the school or the university - in the context of this paper. The method of computing the CGPA is generally given by:

$$
\text { CGPA }=\frac{\text { Total GPTs of all courses taken }}{\text { Total Number of Credits of all courses taken }} .
$$

\subsubsection{Operationalization of the CGPA in UDS}

For a student to graduate in the UDS, s(he) must meet the University's requirement for graduation. The University's requirement is made up of the departmental requirements, the Faculty/School requirements and the CGPA. Since the focus of this study is on using CGPA as an indicator of SAA, the discourse on the university's requirement - for a student to graduate - will be concentrated on the CGPA.

The UDS, just like other universities globally, employs the CGPA as a measurement tool for SAA; and it is computed by taking into account all required courses offered up to current trimester [13]. The CGPA is computed using the formula below:

$$
\mathrm{CGPA}=\sum \frac{T G P}{T C U}
$$

Where:

TGP = Total Grade Points; and it is computed by multiplying grade point score for each course by the corresponding credit unit, and then summed up. 
TCU $=$ Total Credit Units for all courses offered for which the TGP has been obtained and for all other courses that are required to be offered. The TCU is computed by adding credit values of all courses taken. Naturally, the first GPA computation for each student is the same as the CGPA [13].

The CGPA value for each student is folded to two decimal places; and it is usually unfolded to three or more decimal places to reveal discrepancies between two or more CGPA values in the event that there is a tie between or among two or more students in competing for the best graduating studentship based on the CGPA [14]. The class of degree obtained by a student is determined by the CGPA value obtained by the student. Whiles the CGPA value-ranges of 4.50 to 5.00 and 3.50 to 4.49 are respectively narrated as First-Class Honors and Second-Class Honors (Upper Division), CGPA value-ranges of 2.50 to 3.49 and 2.00 to 2.49 are described as Second-Class Honors (Lower Division) and Third Class respectively. 'Pass' and 'Fail' narrations are respectively fitted into the CGPA value-ranges of 1.50 to 1.99 and $<1.50$ [13].

The study uses the CGPA as the indicator of the dependent variable (SAA) because it reflects the overall academic achievement of students in the University; and it remains the most widely used indicator of SAA by other researchers (e.g., [1,9,15]). According to [16], a number of studies have used the CGPA as a measurement of SAA.

In addition, many employers used the CGPA to screen out job candidates and they mostly prefer a candidate with a higher CGPA. Economists argue that an individual's career prospects, future earnings, and standard of living improve when they earn a bachelor's degree. Besides degree attainment, one important measure of achievement in college is a student's collegiate grade point average. A student's undergraduate CGPA can be a determining factor as to whether a graduate is hired by an employer, awarded a fellowship, or admitted to a graduate school. Researchers have found that undergraduate CGPA has a positive impact on earnings [15].

[16] commenting on the work of Jones and Jackson (1990), speculates that an increase in CGPA of one grade point causes an increase in annual earnings of over $8 \%$ due to the strong effect that CGPA can have on earnings and employment. Thus, the use of the CGPA - by this study - as an indicator of SAA was founded on solid grounds.

\section{Methods}

Based on the objectives of this paper, the researchers used the survey technique. The survey technique is more usable if a researcher intends to collect quantitative data and thus, analyze quantitatively; which can lead to description of phenomenon and/or prediction of relationships between or among study variables. A total of 170 final year students were sampled from the target population, which consisted of 362 final-year students of the FMS who were expected to graduate during the $19^{\text {th }}$ Congregation of the University.
A self-designed questionnaire, after it was pilot-tested to assess its readability, ambiguity and the intended information it seeks to solicit, was distributed to the 170 students. A usable 145 questionnaires, which represent about $85 \%$ response rate, were retrieved and coded for analysis. Data were analyzed using Statistical Package for Social Sciences (SPSS) version 25.0 for windows. Cronbach alpha test performed on the data produced a satisfactory score of 0.795 , implying that the instruments had about $79 \%$ chance of producing similar results if re-administered.

The Dummy variable Multiple Regression model was used since gender was measured on a nominal scale. Gender was classified into mutual exclusive categories as:

$$
G=\left\{\begin{array}{l}
1, \text { If student is a male } \\
0, \text { If student is a female }
\end{array} .\right.
$$

For model credibility, the Anderson Darling test for normality, the levene`s test for equality of variances were all satisfied. Further, the Variance Inflation Factor (VIF) value of 4.255 also indicated a moderately weak multicollinearity.

\section{Findings and Discussions}

The study was conducted to investigate the determinants of SAA. The variables considered as determinants, in this study were age of students, their gender and the previous knowledge of their current programs. Therefore, Multiple Regression Analysis (MRA) was performed to determine the effect/impact of each of these determinants on SAA. Table 1 below provides model summary of the MRA.

Table 1. Model Summary of Multiple Regression Analysis

\begin{tabular}{ccccc}
\hline Model & $\mathrm{R}$ & R Square & Adjusted R Square & $\begin{array}{c}\text { Std. Error of the } \\
\text { Estimate }\end{array}$ \\
\hline 1 & 0.765 & 0.605 & 0.601 & 3.175 \\
\hline
\end{tabular}

a. Predictors: (Constant), age, gender, previous knowledge

b. Dependent Variable: Students' Academic Achievement.

The Adjusted R Square value is 0.601 , implying that the age of students, their gender and previous knowledge of their current programs have accounted for about $60 \%$ variation in their academic achievement. The $\mathrm{R}$ Square value indicates the percentage of the variance in SAA explained by age, gender and previous knowledge of current programs (Table 1).

Table 2. Results of ANOVA

\begin{tabular}{ccccccc}
\hline \multicolumn{2}{l}{ Model } & $\begin{array}{c}\text { Sum of } \\
\text { Squares }\end{array}$ & Df & $\begin{array}{c}\text { Mean } \\
\text { Square }\end{array}$ & F & Sig. \\
\hline \multirow{2}{*}{1} & Regression & 763.821 & 5 & 149.855 & 52.615 & $.000^{\mathrm{b}}$ \\
& Residual & 485.417 & 140 & 2.718 & & \\
& Total & 1249.238 & 145 & & & \\
\hline
\end{tabular}

a. Dependent Variable: Students' Academic Achievement;

b. Predictors: Constant, age, gender, previous knowledge.

The value of the F-test and $\mathrm{p}<0.05$ signifies that the model is good fit and it is statistically significant (Table 2). 
Table 3. Multiple Regression Coefficient

\begin{tabular}{cccccc}
\hline \multirow{2}{*}{ Model B } & \multicolumn{2}{c}{$\begin{array}{c}\text { Unstandardized } \\
\text { Coefficients }\end{array}$} & $\begin{array}{c}\text { standardized } \\
\text { Coefficients }\end{array}$ & & \\
\cline { 2 - 4 } & Std. Error & Beta & & S & \\
\hline (Constant) & 47.208 & 2.69 & & 15.951 & .000 \\
Previous & .873 & .050 & .512 & 15.012 & .000 \\
knowledge & .050 & & & \\
Age & .743 & .065 & .301 & 10.956 & .000 \\
Gender & .569 & .069 & .207 & 5.680 & .000 \\
\hline
\end{tabular}

a. Dependent Variable: Students' Academic Achievement

The study was conducted to investigate the determinants of SAA. The contribution of the individual determinants of SAA in the FMS of the UDS is shown in Table 3. When all other determinants are held constant, the regression model indicates the degree to which each determinant influences the dependent variable; and it produces the regression equation below:

$$
\mathrm{SAA}=2.69+0.050(\mathrm{PK})+0.065(\mathrm{~A})+0.069(\mathrm{G})
$$

Where:

SAA = Students’ Academic Achievement

$\mathrm{PK}=$ Previous Knowledge of current program

$\mathrm{A}=$ Age of Student

$\mathrm{G}=$ Gender of Student.

The lesson learnt from the equation above, indicates that SAA will change by 0.050 units (or grades), in the context of this paper, if there is a change in the previous knowledge of the students' current programs; with all the other determinants held constant. SAA is also observed to vary directly with all the determinants since their respective coefficients are all positives values (Table 3 ). Note that negative coefficients will have suggested an inverse relationship between SAA and the determinants.

The ' $\mathrm{t}$ ' and the Beta values reported in the study indicate that the age of students, their gender as well as the previous knowledge of their current programs, to a large extent, predict their academic achievement. The result also indicates the contribution of each determinant to the total contribution/impact on SAA. Thus, students' previous knowledge of their current programs has the highest impact $(\beta=0.512)$ on SAA, followed by students' age $(\beta=0.301)$ and Gender $(\beta=0.207)$ in that order. Further, there was evidence against $H_{1}, H_{2}$ and $H_{3}$. Hence, students' age, the previous knowledge of their current programs, and their gender have significant impact on their academic achievement. This is also because, for all the three determinants, $p v=0.000<0.05$. The findings of the study are consistent with that of $[1,2,5,6,7,8]$.

\section{Conclusion}

The study was conducted to investigate the determinants of SAA. The study concludes that there is significant relationship between the independent variables (age, gender and previous knowledge of students' current programs) and the dependent variable (SAA); with previous knowledge of students' current programs exerting the strongest influence, followed by age and then gender of students.
Management of the University should encourage prospective applicants to apply to seek admission into the programs they offered during their previous training. For example, qualified applicants who offered sciences at their Senior High School level should be given admission to read science programs in the University but not humanities; and the vice versa. A major limitation of the study is that the sample population was selected from only one Faculty - FMS, instead of three or more Faculties/Schools since the University has nine Faculties and five Schools. This has the potency to affect the generalizability of the findings of the study. Moreover, there are several determinants of SAA but the study utilizes only three of them. Therefore, further research needs to be conducted utilizing some of the determinants - income level of parents, learning environment, learning style, teacherfactors and so on - that were left out in this study.

\section{References}

[1] S., V. J., Santhi, B., Noor, A. A., \& Nasirudeen, A. M. (2014). Factors Contributing to Academic Performance of Students in a Tertiary Institution in Singapore. American Journal of Educational Research, 2, 752-758.

[2] Shoukat, A., Zubair, H., Fahad, M., Hamid, K., \& Ahmed, A. (2013, August 01). Factors Contributing to the Students' Academic Performance: A Case Study of islamia University Sub-Campus. American Journal of Educational Research, 1, 283-289.

[3] Ibrahim, A., Elias, N. S., Richard, N. Y., \& Bawah, A. K. (2018, December). Analysis of Graduate Satisfaction and Experience with Higher Education Services in a Ghanaian University. European Journal of Educational Sciences, 5, 14-27.

[4] Faustina, N., Ibrahim, A., \& Abukari, A. (2019, December 4). Multivariate Analysis of Students' Perception of the Impact of Lecturers' Ranks on their Performance at the Faculty of Mathematical Sciences, University for Development Studies-Navrongo, Ghana. Higher Education Studies, 9, 53-62.

[5] Eitle, T. M. (2006, August 20). Do gender and race matter? Explaining the relationship between sports participation and achievement. Journal Sociological Spectrum, 25(2), 177-195.

[6] Chambers, A. A., \& Schreiber, B. J. (2004, January 19). Girls' academic achievement: varying associations of extracurricular activities, Gender and Education. Journal of Gender and Education, 16(3), 327-346.

[7] McCoy, L. P. (2005, August 07). Effect of Demographic and Personal Variables on Achievement in Eighth-Grade Algebra. Journal of Educational Research, 98(3), 131-135.

[8] Peng, S. S., \& Hall, S. T. (1995, February). Understanding RacialEthnic Differences in Secondary School Science and Mathematics Achievement. Research and Development Report. National Center for Education Statistics (ED), U.S. Department of Education. Washington, DC: ERIC. Retrieved July 06, 2018, from https://files.eric.ed.gov/fulltext/ED381342.pdf.

[9] Ervina, A., \& Nor, O. (2005). Undergraduate Students' Performance: The Case of University of Malaya. Quality Assurance in Education, 13(4), 329-343.

[10] Habtamu, S. B. (2017, February 21). Factors Affecting Learning Mathematics in the Case. International Journal of Education, Culture and Society, 1, 6-12.

[11] U.S. Department of Education, N. C. (2003). The Condition of Education 2003. Washington DC: NCES.

[12] Rossi, M. (2017, March). Factors Affecting Academic Performance of University Evening Students. Journal of Education and Human Development.

[13] University for Development Studies. (2014). General and Examination Rules and Regulations on First Degree and Diploma Programmes. Tamale, Northern Region, Ghana: ROA Publishers.

[14] University for Development Studies. (2018). Basic Facts, Statistics \& List of Graduands. Tamale: Mbuk Concepts, Tamale. 
[15] Nirogini, Y., \& Anthony, A. (2017, July). A Study on the Factors Influencing on Grade Point Average (GPA) With Special Reference to Third Year Commerce and Management Students of Eastern university, Sri Lanka. Journal for Studies in Management and Planning, 3(8), 409-425. Retrieved November 15, 2018, from http://edupediapublications.org/journals/index.php/JSMaP/.
[16] Norhidayah, A., Kamaruzaman, J., Syukriah, A., Naja, M., \& Azni, S. A. (2009, December 20). The Factors Influencing Students Performance at Universiti Teknologi MARA Kedah, Malysia. Management Science and Engineering, 3, 81-90. Retrieved January 10, 2018, from Http://www.cscanada.net.

(C) The Author(s) 2019. This article is an open access article distributed under the terms and conditions of the Creative Commons Attribution (CC BY) license (http://creativecommons.org/licenses/by/4.0/). 